\title{
EL DIARIO ÍNTIMO, AZORÍN Y LA NUEVA NOVELA
}

\author{
MONTSERRAT ESCARTíN GUAL \\ Universitat de Girona
}

Diario de un enfermo (1901), la primera novela de Azorín, acaba de cumplir 100 años. Aunque no podemos afirmar que nuestro autor escribiera un diario personal, lo que está claro es su afición al género y a su estructura como vehículo literario desde sus primeros libros. Por ejemplo, Charivari, crítica discordante (1897) es un conjunto de artículos de crítica literaria que muestran, bajo la forma de un ficticio diario, las duras opiniones de José Martínez Ruiz sobre el mundo de las letras madrileño, donde no faltan incidentes vividos. Días después, el autor publica Bohemia, ocho cuentos de tono íntimo, que son confesiones personales apenas noveladas. De ellos, destacamos el primero, Fragmentos de un diario, por su claro fondo autobiográfico (la dura experiencia literaria de los años mozos del escritor como periodista sin empleo durante ocho duros días de marzo de 1897) y la forma de anotación diaria. Al año siguiente, un librito titulado Soledades (1898) insiste en los apuntes periódicos, aunque sin fechas. En él, Martínez Ruiz reúne breves pensamientos, a modo de máximas, que recuerdan mucho el diario personal de Unamuno'.

En Diario de un enfermo, las fechas con que se inicia la novela muestran su cercanía con los textos mencionados. El diario empieza el 15 de noviembre de 1898 y acaba el 6 de abril de 1900, o sea, se abre y cierra en los mismos meses que Charivari, obra que supuso el primer intento de Martínez Ruiz de narrar su profunda crisis literaria y vital después de ser expulsado de El país en 1897. A dicho conflicto profesional se sumó una crisis de ideas políticas (después de ser criticado por su credo anarquista); una crisis vital (que le llevó a posturas abúlicas o de cierto misticismo) y una crisis estética (cuyo resultado fue un cambio de estilo). Es decir, Diario de un enfermo explica lo mismo pero usando el tono intimista de un

\footnotetext{
${ }^{\prime}$ Unamuno escribió cinco cuadernos, redactados entre 1897 y 1902, en paralelo a una profunda crisis espiritual que cambió el rumbo de su vida. Se publicaron por primera vez en 1970 y sus editores titularon al conjunto Diario íntimo, aunque sería más apropiado hablar de un texto íntimo y no de un diario, pues se trata de anotaciones atemporales carentes de la cotidianidad que definen al género.
}

Rlit, LXIV, 127 (2002), 107-120 
fingido diario. De ahí que el aparente género elegido pueda ser definido con propiedad de «íntimo» frente al usado en Charivari, obra donde la anotación diaria de hechos externos nos obligaría a hablar de «dietario» ${ }^{2}$. Dicho de otro modo, los acontecimientos vividos por nuestro novelista entre 1897 y 1900 son suficientemente importantes como para analizarlos por escrito; unos, en el ámbito público, anotando a modo de dietario: sucesos, encuentros, habladurías de café (los artículos de Charivari); y otros, imitando un diario íntimo en el terreno de la ficción, con los sentimientos que esas mismas experiencias despertaron en su protagonista (Bohemia, Diario de un enfermo).

Después de todos estos experimentos, no nos sorprende que el autor titulase su primera novela: «diario» y que las siguientes hayan sido calificadas por la crítica de «autobiografía espiritual»o «documentos testimoniales», en cuanto que contienen datos importantes para el conocimiento de la vida íntima de su creador. La voluntad - escrita a la vez que Diario de un enfermo y publicada al año siguiente- empieza con un prólogo donde el autor afirma que saca datos de un supuesto diario encontrado: «Y el autor de un Diario inédito, de donde yo tomo estas notas, escribe:...» ${ }^{3}$, igual que en Diario de un enfermo: «Lector: lee religiosamente estas breves páginas. En ellas palpita el espíritu de un angustiado artista [...] fue dejando en estos diarios y tormentosos apuntes su alma entera» ${ }^{4}$.

Para fingir con verosimiltud ser un diario, esta novela presenta temporadas de anotación constante, varias en diferentes momentos de un mismo día, otras en blanco...; y, en el contenido, secretos de la vida de su protagonista: una experiencia amorosa, una crisis personal, instantes de recogimiento interior, momentos de catarsis emocional, reflexiones, dudas como artista..., que nos permiten calificarlo de «íntimo». El diario se convierte así en refugio del personaje ante los problemas que le causa su vida pública de periodista o en medicina para su carácter de hombre solitario, triste, que sólo se relaciona bien consigo mismo. Su nihilismo se simboliza en una enfermedad espiritual - clave del título - que busca curación en la escritura, ya que como decía Amiel: «un diario es la farmacia del alma» ${ }^{5}$.

Recordemos que, durante su crisis juvenil, Azorín sufrió el conflicto de hallarse dividido entre su actividad pública de periodista y su naturaleza contemplativa y solitaria. Este malestar, que se transparenta en las obras del momento, se convierte en el tema central de Diario de un enfermo, donde el citado dualismo vida-libros es el conflicto existencial del protagonista. Tanto en Diario de un enfermo como en La voluntad o Antonio

${ }^{2}$ Vid. el resumen de las obras del autor al final de este artículo.

3 J. MARTínez Ruiz, Obras selectas, Madrid, Biblioteca Nueva, 1943, p. 80.

${ }^{4}$ J. MARTínez RuIZ, Diario de un enfermo, Madrid, Biblioteca Nueva, 2000, p. 147.

${ }^{5}$ F. AMIEL, En torno al diario íntimo, Valencia, Pre-Textos, 1996, p. 115. 
Azorín, el personaje central es un individuo que lucha entre la vida y el arte. Es decir, entre hacer o contemplar, entre sentir o pensar:

\begin{abstract}
Tenía fe en los libros; los compraba a montones... y poco a poco he ido viendo que en el fondo todos dicen lo mismo, y que con leer cincuenta $-\mathrm{y}$ creo que es mucho- se han leído todos. [...] el ardor ha pasado y ahora domino yo a los libros y no ellos a mí. Cuando se ha vivido algo ¿para qué leer? ¿Qué nos pueden enseñar los libros que no esté en la vida? ${ }^{6}$
\end{abstract}

Por lo tanto, Diario de un enfermo es la primera de una serie de obras - La voluntad (1902), Antonio Azorín (1903), Las confesiones de un pequeño filósofo (1904) - que seguirán analizando cuál de las dos es la mejor actitud ante la vida. Así, del joven escritor que acaba suicidándose en la primera, al filósofo de la última, hombre maduro que puede perdonar con humor, vemos todo un proceso de crecimiento anotado en escritos supuestamente autobiográficos. Visto lo cual, 'la pregunta surge por sí misma: ¿Por qué nuestro autor jugó con los llamados géneros del yo en sus novelas? Tal vez influyó en él la literatura de los diarios confesionales, cuyo ejemplo máximo fue el Journal intime de Frédérich Amiel, obra mencionada por Martínez Ruiz en La voluntad ${ }^{7}$. También, el diario de Unamuno, quien solía enseñarlo a los amigos que mantenían una relación intelectual con él, o el de Jules y Edmond Goncourt ${ }^{8}$.

Probablemente, el autor de Diario de un enfermo recibió el influjo de Charles Demailly (1851), novela de los Goncourt primero titulada Les hommes de lettres, cuyo protagonista escribe un diario personal: Memorias de mi vida muerta. Martínez Ruiz la leyó mientras redactaba Diario de un enfermo y, aunque no la tradujo totalmente, sí hizo su revisión final antes de aparecer publicada por entregas en la Revista Nueva ${ }^{9}$. No sólo Diario de un enfermo, otras muchas narraciones de esos años siguieron como modelo el relato de los Goncourt, como explica José M. ${ }^{a}$ Valverde:

La influencia de Charles Demailly en los escritores de aquel ambiente y momento llega a constituir casi un «sub-género» literario [...] era la novela del escritor, en cuanto tal escritor, con una leve pero trágica trama sentimental -fracaso de su matrimonio con una mujer superficial, hasta acabar en locura-, y largas descripciones de estados de ánimo, y más aún, de ambientes bohemios de literatos y periodistas ${ }^{10}$.

Le influyera quien le influyera, Martínez Ruiz vio las ventajas expresivas del género del diario íntimo para plasmar las crisis y conflictos espi-

\footnotetext{
${ }^{6}$ J. MARTÍNEZ RuIZ, La voluntad, en Obras selectas, op. cit., 174.

7 Ibídem, 116.

${ }^{8} \mathrm{Al}$ morir su hermano Jules, Edmond continuó su redacción durante 25 años.

${ }^{9}$ El relato empieza a publicarse en el $\mathrm{n}^{\circ}{ }^{\circ} 1$, en febrero de 1899 , y termina en el n. ${ }^{\circ} 16$, el 15 de julio de 1899 .

10 J. M. ${ }^{a}$ VAlVerde, Azorín, Barcelona, Planeta, 1971, p. 122.
} 
rituales de un hombre. De hecho, una de las razones por las que el alicantino admiraba a Leopardi era su interés por captar las variaciones de un individuo a través del tiempo, motivo que llevó al italiano a escribir su propio diario. Nuestro novelista comparte dicha preocupación:

\begin{abstract}
Leopardi tiene razón: ningún mayor dolor que estrechar entre nuestros brazos un ser querido que antes tenía un pergueño y ahora tiene otro [...] Es el mismo ser querido y no es el mismo, no. [...] La imagen placiente que teníamos de la persona amada es sustituida por otra imagen dolorosa. Y cuando la persona amada muere, es esta imagen y no la otra, la que conservamos. Y así se pierde enteramente la persona amada ${ }^{11}$.
\end{abstract}

De modo parecido, el protagonista de Diario de un enfermo analiza la evolución de su compañera a lo largo de la enfermedad y la suya propia. $\mathrm{Si}$ somos una serie de yoes anteriores que siguen presentes en una existencia subterránea del espíritu, no es extraño que Martínez Ruiz eligiera el diario como ámbito donde salvar la sucesión de estados por los que pasaba su persona en época de cambios tan radicales.

Es dicha obsesión por los procesos, la evolución y el tiempo que huye lo que despierta la atracción del autor por los llamados géneros del yo. Como Proust, su objetivo era salvar lo ya vivido. Sabemos que Goethe aconsejaba llevar un diario personal como forma de no olvidar nuestro ayer y preparar el mañana, dado que el diario preserva de la destrucción las sucesivas etapas del hombre a lo largo de su vida. Ello es bueno porque, al conservar lo vivido, mostrar la evolución y concretar los deseos futuros, lo escrito da mayor plenitud y realidad a la existencia de su autor. Amiel decía: «...'Si nos acordáramos de todo lo que hemos observado o aprendido en la vida, qué sabios seríamos'. Este pensamiento bastaría para hacernos llevar un diario asiduo» ${ }^{12}$. En el fondo, a Azorín le movió siempre el sueño de triunfar en el mundo literario y ese hecho marcó toda su obra; de ahí su necesidad constante de autoevaluación y análisis, explícita en novelas, diarios o memorias.

Para entender Diario de un enfermo, hemos de considerar otro hecho fundamental: cuando, en 1899-1900, nuestro escritor se plantea la creación de un supuesto diario íntimo, se halla ante una ausencia de modelos en español de este género ${ }^{13}$. A pesar de esa falta de tradición, hemos de re-

\footnotetext{
1 J. MARTínez Ruiz, Valencia, en Obras selectas, op. cit., 868.

12 F. AMIEL, op. cit., 89-90.

13 «Si dejamos de lado el breve texto que se encontró entre los papeles de Unamuno, escrito con ocasión de una crisis espiritual y que los editores han publicado bajo el título bastante discutible de Diario íntimo, no se puede hablar de verdadero diario íntimo en España hasta 1918, fecha de inicio de los de Josep Pla y Marià Manent, ambos en lengua catalana. Habrá que esperar a la generación del exilio bien entrada la posguerra (Rosa Chacel) y a los intelectuales catalanes que escribían en castellano (Jaime Gil de Biedma, Carlos Barral) para que se reanude el género», L. FreIXAS, en F. AMIEL, op. cit., 22.
} 
cordar que Martínez Ruiz era un gran conocedor de las letras francesas y, si bien no tenía referentes españoles a los que acudir, la cultura vecina, sin duda, le ofreció alternativas, entre las que destacan —además de Amiel-, los hermanos Goncourt, cuyo diario es su obra maestra, o Michael de Montaigne, en cuyos Essais se mezcla lo íntimo con lo público, lo histórico con lo sentimental, lo erudito con lo subjetivo.

¿Y cómo surge en el autor esta temprana afición por crear obras literarias en forma de apunte personal donde lo novelístico se mezcla con la racionalidad del ensayo, lo fragmentario del artículo de periódico y la intimidad propia del diario? Ya que son las características propias de este último género - la primera persona narrativa, el tono confesional, la observación anotada del suceso cotidiano, la subjetividad...-, las que acabarán constituyendo el llamado estilo Azorín, consolidado en futuras novelas.

Con independencia de que Martínez Ruiz escribiera o no un diario, lo que nos importa es valorar por qué le gustaba su técnica y para qué la traslada a la creación literaria. La primera causa nacería del deseo de entender o salir de su crisis juvenil, ya que, ante todo, un escritor que redacta un diario intenta establecer quién es él, objetivo comprensible en su caso. La segunda, hallar un género que le permitiera plantearse un conflicto, heredado de Unamuno y de Amiel, que le interesó toda la vida: encontrar la identidad de la persona dividida entre lo público y lo privado y estudiar el yo como un proceso cambiante a lo largo del tiempo, que se puede captar bien en el fragmentarismo del diario (mejor que en la continuidad de la autobiografía). Si Amiel afirma: «Asisto a mi metamorfosis, ya no soy lo que era» ${ }^{14}$, en su libro de memorias, Valencia (1941), Azorín confiesa:

«Soy otro, soy otro». O sea: antaño fui un hombre escritor llamado «Ahrimán» y «Cándido», luego otro hombre escritor que firmaba sus obras con el nombre de José Martínez Ruiz, y después otro, Antonio Azorín, y poco más tarde otro, Azorín a secas, y ahora otro que ya no sé si es ese mismo Azorín en trance de envejecer o alguien más o menos nuevo respecto del que antaño publicó Castilla [...] Todos ellos esencialmente distintos entre sí, todos entre sí «otros» 15 .

Prueba de su sentimiento de otredad son los múltiples pseudónimos con los que firmó sus artículos periodísticos: J. Martínez Ruiz; sus iniciales JMR; Cándido, personaje de Voltaire; Ahrimán (o A.), dios del mal de la mitología persa; Don Abbondio, el cobarde párroco de Los novios, de Manzoni, etc.

La tercera razón podría ser la sinceridad ante uno mismo, que el diario permitía al ser un género propicio a la confesión o reflexiones por escrito.

\footnotetext{
${ }^{14}$ F. AMIEL, op. cit., 89.

${ }^{15}$ P. LAín EnTRalgo, «Azorín: el mismo, pero de otro modo», Revista de Occidente, n. ${ }^{\circ} 133$, abril de 1974 , pp. 40-41.
} 
De hecho, la tendencia del alicantino al recogimiento y a la privacidad - como buen tímido- le hacen partidario de géneros intimistas como diarios, cartas y, sobre todo, memorias; género que cultivó a lo largo de su vida para resumir diversas etapas de la misma. Su obra Valencia, 1941, recoge sus años de estudiante en la ciudad levantina; Madrid, 1941, de joven periodista en la capital, y Memorias, 1943 (ampliada en 1946 bajo el título Memorias inmemoriales), refiere su vejez en la misma ciudad. Por último, París, 1945, evoca los años de exilio vividos en la capital francesa. En todos estos libros ${ }^{16}$, Martínez Ruiz es el protagonista y no otras figuras o sucesos de la época, con lo cual se evidencia la delgada frontera que existe, para nuestro autor, entre las memorias y la autobiografía estricta.

Pero éstas no son las únicas razones que empujaron a nuestro escritor hacia el diario. La principal fue la búsqueda de una técnica que le ayudara a crear su nuevo concepto de novela. El género del diario le ofrecía, sobre todo, la posibilidad de concebir textos con una cierta autonomía entre ellos, una cronología discontinua, la confesión subjetiva, el uso de la primera persona..., técnicas que podían ayudarle a romper con la forma ortodoxa del relato decimonónico. Además, el diario requiere del presente, o del presente perfecto, dada la inmediatez de los hechos que se narran muy cercanos al momento de su redacción. Escribir sobre vivencias propias e inmediatas en lo personal (un diario) es algo parecido a hacerlo sobre los sucesos sociales y recientes en un periódico (un artículo cada día) y Martínez Ruiz, como buen periodista, no debió de tener muchas dificultades en pasar del terreno de lo público a lo privado, con una técnica fragmentaria muy semejante, para crear un estilo basado en unidades breves y autónomas aplicable a ensayos o novelas. Si el artículo de periódico pudo estar en el origen de dicha técnica formal, el apunte del diario también, aportando el continuado análisis de la experiencia íntima. Por ello, no es de extrañar que en La voluntad y Antonio Azorín, obras donde ya no se mantiene la estructura del diario, aún queden momentos en los que su estilo se conserva; concretamente en la tercera parte de ambas, donde el protagonista habla de sí mismo en primera persona comentando su vida. En La voluntad leemos: «Esta parte del libro la constituyen fragmentos sueltos escritos a ratos perdidos por Azorín. El autor decide publicarlos para que se vea mejor la complicada psicología de este espíritu perplejo» ${ }^{17}$. En las dos novelas, el escritor consigue - al usar la tercera persona y luego la primera - fundir la labor del periodista que narra lo que ha sucedido en el pasado reciente con la del autor de diarios, al anotar con asiduidad lo íntimo. Por lo tanto, podríamos concluir que es la relación con lo

\footnotetext{
${ }^{16}$ Vid. la relación de obras del autor vinculadas con los géneros del yo al final del artículo.

17 J. MARTínez Ruiz, Obras selectas, op. cit., 172.
} 
inmediato, que relaciona el diario y el artículo, lo que lleva a nuestro autor a elegir rasgos de ambos géneros para hablar de sus vivencias en la literatura (Bohemia, Diario de un enfermo, La voluntad, Antonio Azorín); sin embargo, cuando lo descrito va al pasado, elige la forma de las memorias (Valencia, Madrid, Memorias inmemoriales o París).

Yendo más allá, no podemos hablar de Martínez Ruiz y su primera novela como de un ensayo individual en el género de lo autobiográfico, que después continúa en su trilogía, sino del exponente de una tendencia finisecular que se refleja en obras como: Declaración de un vencido, de A. Sawa; Cuesta abajo, de Clarín; La lámpara maravillosa, de Valle Inclán; Cómo se hace una novela, de Unamuno; Camino de perfección, El árbol de la ciencia, de Baroja... Este autor, el mismo año 1901, escribió un cuento titulado Diario de un estudiante ${ }^{18} \mathrm{y}$, antes, otro Diario de un desespera$d o^{19}$, con técnica y argumentos muy parecidos a los de Azorín. El contenido de Diario de un desesperado es la supuesta transcripción de las pocas páginas de un diario salvadas del fuego, donde se describe el viaje del protagonista, hombre de negocios arruinado que huye de Madrid a un pueblo de Aragón buscando paz. Tras permanecer allí varios meses - de agosto a diciembre-, su malestar aumenta y decide suicidarse, acto que evita su familia. El cuento acaba con una definición del suicidio como acto propio de hombres enfermos, de carácter débil. En Diario de un estudiante, el protagonista anota su sentir durante un viaje que realiza el 18 de marzo de 1901, de Madrid a Ávila, donde visita iglesias, conventos en las afueras, etc., y termina tomando un tren para Burgos, de modo muy parecido a los protagonistas de Diario de un enfermo y Camino de perfección, novela en cuyo final también se utiliza la forma del diario ${ }^{20}$.

Esta similitud de los relatos juveniles de Baroja y Martínez Ruiz (cuentos breves, en forma de diario, con el trasfondo de un viaje, para enmarcar a un personaje angustiado y «enfermo») nos hacen ver la complicidad estética entre ambos amigos y la influencia del vasco en el alicantino. Diario de un enfermo recoge muestras de esa amistad: desde la presencia de Baroja como personaje -Olaiz-; a la descripción de episodios vividos por los dos escritores en Toledo, fruto de un viaje real del que tenemos constancia en las memorias de sendos novelistas. De esa excursión de tres días en diciembre de 1900, destaca una anécdota que ambos literaturizaron en la que un hombre porta un ataúd de niño sin encontrar la casa a la que va

${ }^{18}$ Publicado en Electra, el 6-IV-1901.

19 Publicado en La justicia, el 8-I-1894.

20 «¿Fue manuscrito o colección de cartas? No sé; después de todo, ¿qué importa? En el cuaderno de donde yo copio esto, la narración continúa, solo que el narrador parece ser en las páginas siguientes el mismo personaje. Ya no podía vivir allí. Tomé el tren...», P. BARojA, Camino de perfección, Madrid, Caro Raggio, 1974, p. 277. La cursiva es nuestra. 
destinado. Éste y otros sucesos toledanos (la comida con el gobernador, la descripción de un convento de monjas, la contemplación de cuadros de El Greco...) son recreados tanto por Baroja, en Camino de perfección, como por Martínez Ruiz, en Diario de un enfermo y La voluntad ${ }^{21}$.

Los desplazamientos de estos personajes dan a la trama de sus novelas una cierta unidad, que nos obliga a relacionar el apunte de viajes con el del diario íntimo. Como un nuevo homo viator, el protagonista de Diario de un enfermo viaja a Toledo, Levante y Lantigua, anunciando la movilidad inquieta del Azorín de La voluntad y Antonio Azorín. Si los personajes de Martínez Ruiz, como los de Baroja (Diario de un desesperado, Diario de un estudiante, Camino de perfección), anotan sus sensaciones a través de sendos viajes es por algo más que una casualidad. La inquietud lleva a la acción; pero la acción sin un objetivo es absurda y se convierte en simple huida que no detiene el malestar ni la sucesión de más viajes sin objetivo. La conciencia de ese absurdo llevará a los personajes a probar la actitud contraria: el quietismo, la contemplación estática de la belleza natural o artística, en la llamada estética del reposo.

Para Martínez Ruiz, la vida como viaje iniciático se suma al viaje de la creatividad artística, es decir, al descubrimiento de la propia realidad de escritor, en un proceso que empieza en Diario de un enfermo, con una obra malograda, avanza en La voluntad y culmina en Antonio Azorín al ser escrita. Por ello, hay quien sostiene la teoría de que partes de Antonio Azorín o de La voluntad se redactaron simultáneamente a Diario de un enfermo, como tres intentos de escribir una nueva novela o prosa artística; frente a quien afirma que fragmentos de Antonio Azorín y Diario de un enfermo se redactaron a la vez y antes que La voluntad ${ }^{22}$. Así, Diario de un enfermo fue un borrador y Antonio Azorín, la primera versión de La voluntad, novela que Martínez Ruiz quería escribir o segunda versión, más elaborada y que expresa mejor sus conflictos y actitud ante la vida. En las tres, hay muchos parecidos de contenido, tono y estilo, pudiendo decirse que algunos párrafos suponen versiones distintas de una misma idea.

Que las tres novelas son variaciones de una sola obra se evidencia tan-

${ }^{21}$ J. M. ${ }^{\mathrm{a}}$ VALVERDE, op. cit., 152-159, compara las tres versiones del episodio del ataúd en Diario de un enfermo, La voluntad y Camino de perfección, sin poder establecer el orden de sucesión cronológica ni los influjos mutuos. Martínez Ruiz habla de dicho viaje en varios capítulos de Madrid: «Luna en Toledo», «Monjas de Toledo» y «El cardenal Romo».

22 «La redacción primitiva de Antonio Azorín es coetánea, más o menos, de los fragmentos del Diario de un enfermo. [...] parte de Antonio Azorín se redactó con anterioridad a $L a$ voluntad y más o menos al mismo tiempo que Diario...», E. INMAN Fox (ed.), J. MARTíneZ RUIZ, Antonio Azorín, Barcelona, Labor, 1970, pp. 16-26. Tesis contrastada por M. M. ${ }^{a}$ PÉReZ LóPEZ (ed.), J. MARTíneZ Ruiz, Antonio Azorín, Madrid, Cátedra, 1991, pp. 51-52, quien cree que Antonio Azorín es posterior a Diario de un enfermo y La voluntad, escritas a la par. 
to en la forma, por la técnica diarística que aparece en toda la novela Diario de un enfermo y en la tercera parte de La voluntad y de Antonio Azorín, donde el narrador desaparece y recupera la voz el yo del protagonista ${ }^{23}$; como en el contenido, por la psicología del personaje principal. Si Diario de un enfermo es el inicio de la crisis de un individuo, La voluntad nos muestra su desarrollo y consecuencias, y Antonio Azorín, el ser escéptico que surge de ella, es obligado entender esta breve novela, en relación con las demás, como el origen de todo un proceso vital y artístico. Sigamos esta evolución mediante tres ejemplos, empezando por el tema de la creatividad del escritor, que está bloqueada en Diario de un enfermo y La voluntad, porque el protagonista duda de sí mismo, mientras que, en Antonio Azorín, se soluciona, ya que el personaje escribe la obra literaria que sus antecesores no han podido crear por sentirse más seguro de sí, aunque escéptico y sin ideales. Otra prueba sería advertir cómo el dualismo vida o pensamiento, en que se debate el protagonista de Diario de un enfermo y La voluntad, es superado en Antonio Azorín, novela que muestra ambas posiciones en dos personajes: Verdú — reflexivo- y Sarrió —vital-, indicando que el conflicto sigue vivo; pero el protagonista ya lo ha trascendido. Por último, si en Diario de un enfermo el protagonista afectado de nihilismo se suicida, en La voluntad, se sobrepone a su dolencia casándose con Iluminada y, en Antonio Azorín, no sólo asume su personalidad y aprende a vivir con el dolor, sino que lo convierte en arte.

En consecuencia, podemos afirmar que la trilogía de Martínez Ruiz -entendiendo por tal Diario de un enfermo, La voluntad y Antonio Azorínes un estudio novelado de su vida juvenil; no una autobiografía, sino una creación literaria que analiza la psicología cambiante de su autor a través de la expresión sucesiva del yo en diferentes obras. Es decir, si partes de las tres novelas fueron escritas simultáneamente, ello indica que son diferentes obras pero un mismo material personal que se revisa de nuevo. En cada libro o versión, se destaca una faceta de Martínez Ruiz (pasividad, quietud), o se reescribe el mismo proceso nihilista dándole una solución distinta (suicidio, conformidad con la crisis, aprovechamiento de la misma). Si vamos a la novela siguiente, Las confesiones de un pequeño filósofo, el autor da un paso más inventando a un hombre maduro que, aún sabiendo que dicha «enfermedad» no se puede vencer, construye una filosofía para manejarla de manera digna, aceptando la crisis y aprendiendo a vivir en un mundo sin valores.

Así se cierra la evolución de este personaje novelesco donde se ha estudiado Martínez Ruiz: desde un joven escritor anarquista, pasando por un intelectual que lee de continuo, buscando soluciones a su crisis nihilis-

${ }^{23}$ «...evocando la forma del diario son varios los capítulos que empiezan con un "Hoy..."», Ibídem, 65. 
ta, a un filósofo de temperamento estoico, que mira a los hombres desde su vida retirada. Este sabio, reflejo del desencanto del autor y su generación, tiene una filosofía sencilla: dejar de dar importancia al modo de pensar racional y valorar más la sensibilidad y las emociones. Quizá este proceso sea el del mismo autor que decidió, finalmente, adoptar el nombre de su personaje al reconocerse en su recorrido vital. Con esta identificación, el autor ponía fin a su crisis personal y artística, dando paso a su nueva manera de pensar y escribir conocida como estilo Azorín.

Esta búsqueda de un modo de novelar propio fue común a otros escritores del momento. Me refiero al propósito de crear una nueva novela - llámese novela lírica, antinovela, novela filosófica, ideológica, nivola...-, por parte de los autores del 98. Su objetivo era denunciar la crisis de la estética del realismo-naturalismo con planteamientos simbolistas o impresionistas, fundiendo la prosa con la poesía y la filosofía con la narración. Martínez Ruiz trató, como ellos, de eliminar o reducir al mínimo todos los elementos de una novela clásica: el argumento, el tiempo, el diálogo, la estructura narrativa -que exige una intriga, un clímax y un final concluyente-, el dramatismo e, incluso, el argumento. De hecho, en las novelas de Martínez Ruiz no pasa nada, pero cuántas sensaciones se sienten, resultado de su modo de entender la literatura: «El arte es la captación y gradación de los matices» ${ }^{24}$. Por ello, Diario de un enfermo es una novela diario, no de acciones, sino de matices e incidentes nimios que han conmovido a su protagonista. Es decir, el autor suprime la historia externa y da sólo las sensaciones íntimas del personaje, como había aconsejado Amiel en su diario:

Las impresiones más delicadas son las más fugitivas; si no se expresan al instante, se evaporan [...] Y resulta que esas sensaciones fugaces [...] que pasan por nuestra vida, son justamente lo que ésta tiene de más precioso. [...] En vez de anotar las actividades de cada día, los hechos groseros sin interés, buscar la música interior de las cosas; [...] en vez del itinerario del viajero, sus impresiones de viaje, $[. .$.$] la vida subjetiva captada en su consciencia, más que$ narrada en sus actos ${ }^{25}$.

En su nueva novela, Azorín se complacerá en lo vulgar, pequeño e interior y elegirá hechos cotidianos, que nunca nos impresionan por raros ni desagradables. La atención se centrará en lo insignificante, la acción mínima, inexistente, el gusto por lo íntimo y, en apariencia, poco importante. Para explicarlo, Azorín cita a Racine: «toda invención consiste en hacer algo de nada» ${ }^{26}$. Al ser ámbito de lo anodino, el género del diario sirvió a Martínez Ruiz como modelo de un estilo intimista, sencillo, claro,

${ }^{24}$ J. MARTíneZ RuIZ, cap. III de La isla sin aurora (1944), en J. M. ${ }^{a}$ MARTíneZ CACHERO, Las novelas de Azorín, Madrid, Ínsula, 1960, p. 38.

${ }^{25}$ F. AMIEL, op. cit., 80-81.

${ }^{26}$ J. MARTínEZ RUIZ, «sólo me complace lo sencillo: hacer algo de nada: la fórmula raciniana es para mí el culmen del arte», París (1944), en J. MARTínez CaChero, op. cit., 39. 
alejado de la retórica demasiado literaria y propicio para un nuevo material hecho de matices, sensaciones o silencios, apto para transformar la intimidad de los personajes en un verdadero paisaje. Recordemos que, en la novelística de este autor, los escenarios naturales dejan de ser un decorado y se convierten en estados de ánimo y protagonistas del relato como creía Amiel y los noventayochistas ${ }^{27}$.

La forma de un supuesto diario íntimo, con sus bloques desconectados, iba muy bien al autor para simbolizar tanto las piezas de un mundo que se derrumbaba, como una nueva manera de mirar más moderna y cinematográfica ${ }^{28}$. El fragmentarismo era una técnica, ya usada por el Nouveau roman francés, que Martínez Ruiz eligió para crear un nuevo tipo de novela imitando la estética de los hermanos Goncourt, cuyas novelas parecen confesiones tomadas de sus carnets de notas y fragmentos de sus diarios. Azorín confiesa gustar de la técnica de los Goncourt, porque: «no dan una vida, sino fragmentos, sensaciones separadas... Y así el personaje, entre dos de estos fragmentos, hará su vida habitual...» ${ }^{29}$ Así pues, la nueva novela azoriniana aparenta ser un diario íntimo como técnica narrativa para romper el esquema del relato decimonónico, lo mismo que hacen otros autores al usar también los géneros del yo (Unamuno elige las memorias en Abel Sánchez ${ }^{30}$ o San Manuel, bueno, mártir; Valle-Inclán, en las Sonatas ${ }^{31}$; o Baroja, en El árbol de la ciencia ${ }^{32}$. En el futuro, Azorín creará sus nove-

${ }^{27}$ Las descripciones subjetivas expresaron, también, la personal vibración de Azorín ante la tierra de España, convirtiéndole en un paisajista relevante. Vid. El paisaje de España visto por los españoles.

${ }^{28}$ Azorín escribió varios artículos sobre cine insertos en: La farándula (1945), Ante las candilejas (1947) y Escena y sala (1947). Destacamos dos libros que recogen sus impresiones sobre el séptimo arte: El efímero cine y El cine y el momento.

29 J. MARTíneZ RUIZ, La voluntad, en Obras selectas, op. cit., 115-116.

30 «Estoy seguro de que esa 'Confesión' de Joaquín Monegro eran páginas que el propio Unamuno había escrito en diversos momentos de su vida al meditar sobre el tema de la envidia», J. L. Abellán (ed.), M. DE UnAmuno, Abel Sánchez, Madrid, Castalia, 1987, p. 11.

31 Sonata de otoño se gestó durante una convalescencia de Valle-Inclán que duró tres meses del año 1901, tras ser operado de un pie. Sus páginas fueron la base de la novela, como él mismo explica: «...Estuve tres meses en cama, me olvidé de las minas de la Mancha y escribí unas "Memorias"... Se las leí a A. Machado y a F. Villaespesa. Este, bien hube terminado la última cuartilla, dijo alborozado: "Esto se parece a La Virgen de la Roca, de D'ANNUNZIo". Y Machado añadió: "¡Es magnífico!”. Aquellas "Memorias" son Sonata de otoño». Valle-Inclán, en O. GUERRERO, Valle-Inclán y el Novecientos, Madrid, Magisterio Español, 1977, p. 72. Son destacables: la fecha de redacción de estas memorias -1901 - la referencia a la estética de D'Annunzio y el contenido de la Sonata de otoño - final de una historia de amor por muerte de la amada enferma y delectación en su agonía final- para comparar la obra con Diario de un enfermo de J. MARTínEZ RUIZ.

${ }^{32}$ En las memorias de BAROJA, Desde la última vuelta del camino. Memorias, VII vols., Madrid, Caro Raggio, 1944-1949, la parte titulada «De estudiante de medicina» 
las repitiendo un número parecido de cuadros, estampas o piezas independientes de la misma extensión, trascendiendo el concepto de capítulo. Esa tendencia a separar es lo que podríamos llamar impresionismo en la novela, gracias al cual se quiere expresar cada estado de ánimo e impresión, aislada de otras, sin vínculos lógicos, lo que se traduce en frases yuxtapuestas y sin nexos. El resultado es un estilo entrecortado, estático y repetitivo.

También la condición de los personajes - siempre un mismo tipo humano parecido al autor, definido como ser libresco que actúa y se define por el intelecto-, hace que todas las novelas de Azorín tengan el aire de autobiografías: no en vano es el autor contemporáneo más autorretratado, aunque, a pesar del abundante material que da de sí mismo, vemos siempre al escritor, no al hombre revelando sus sentimientos. Azorín, convertido en personaje, suele hablar sobre todo de los problemas de la creación literaria (génesis de la obra, contratiempos en el proceso creador, etc.). En Diario de un enfermo, en concreto, el diario íntimo le da pie para explayarse en deficiencias sobre las dificultades en el proceso de redacción. De hecho, muchos escritores anotaron en sus diarios las dudas que la creación de una novela les estaba planteando en aquel momento.

En resumen, en la nueva novela finisecular, desaparece el mundo real bajo la mirada subjetiva de los autores que reivindican el yo como único punto de referencia válido para conocer el entorno. Por ello, en estas obras, importa más la manera de mirar que lo visto. Ante dicho planteamiento, el género del diario ofrece una buena excusa para las sensaciones, los sentimientos y las impresiones personales. Es decir, para entender Diario de un enfermo hay que situar a Martínez Ruiz, además de frente a un género sin tradición y en el contexto del 98 , en una época que cultivó un cierto narcisismo, más allá de los límites de un país y tendencia estética (Simbolismo, Decadentismo, Prerrafaelismo), en la última década del siglo. Nos referimos al uso del yo como criterio de valor estético y moral. Así define ValleInclán su ideal artístico: «buscarme en mí mismo y no en los otros», ya que, según él: «si en la literatura existe algo que pueda recibir el nombre de Modernismo, es, ciertamente, un vivo anhelo de personalidad»; por ello, se advierte «en los escritores jóvenes más empeño por expresar sensaciones que ideas» ${ }^{33}$, lo que da como resultado una literatura narcisista, ensimismada e intimista. En suma, el imperioso deseo de mostrar el yo es uno de los rasgos caracterizadores de la nueva literatura, consecuencia del movimiento rebelde que nace con la Modernidad y que permite entender

fue tomada, casi palabra por palabra, de El árbol de la ciencia, prueba de que - para Baroja - la fusión de autobiografía y novela constituye la única realidad.

${ }^{33}$ R. M. a DEL VALLE-INCLÁN, «Breve noticia de mi estética cuando escribí este libro», en El Modernismo visto por los modernistas, Barcelona, Labor, 1980, p. 192. 
la elección de la forma genérica del diario y del material autobiográfico como uno de sus gestos provocadores.

Esta perspectiva que reivindica lo subjetivo como criterio artístico se explica porque, si el realismo-naturalismo había utilizado la razón, la nueva estética modernista expresará el irracionalismo a través de la subjetividad del yo. Es idea de Schopenhauer creer que no hay más mundo que el que nuestra consciencia crea, a través de nuestras sensaciones. Tal vez, por ello, la sensación y lo vivido sean elementos tan importantes donde asentar las creencias, pues son «lo sucedido en un sujeto» y el diario, la fijación por escrito de esa experiencia fugaz, de la que nacerá la seguridad de su protagonista. En este sentido, Diario de un enfermo y las tres novelas posteriores constituyen una biografía de lo sentido, no de los hechos vividos en sí, los cuales importan menos que la forma de recordarlos. En lo moral, el diario afirma lo que siente el hombre en su individualidad y el valor de su espíritu frente a su ser social. O, como explica Amiel: «Mi diario es mi procedimiento para sentir que existo» ${ }^{34}$. Esta actitud lleva a Azorín y a otros escritores hacia la autobiografía, no para recordar su pasado ni por vanidad, sino como sistema de autoconocimiento irracionalista. Si vivir supone ir cambiando, autobservarse es el único modo de aprendizaje utilizando la propia vida. Como dice Amiel: «El edificio de tu existencia es complicado y frágil [...] No te abandones a ti mismo y no interrumpas tu educación; es decir, no descuides este diario» ${ }^{35}$.

Este método contemplativo es el que Martínez Ruiz aplica a su estética en un estilo descriptivo-pictórico de tempo lento. Porque, en definitiva, la tarea autobiográfica no sólo consiste en explicar lo ocurrido, sino en dar sentido a los hechos de la vida a partir de la necesidad de narrarlos como se piensa y siente que ocurrieron.

RESUMEN DEL USO DE LOS LLAMADOS ESCRITOS DEL YO EN JOSÉ MARTÍNEZ RUIZ, AZORÍN

(1897) Charivari, crítica discordante, conjunto de artículos, diario ficticio del 25-XI1896 al 2-IV-1897 [dietario].

(1897) Bohemia. Cuentos, «Fragmentos de un diario» (del 11-III-1897 al 23-III-1897). Las anotaciones son de 8 días de marzo de 1897: el 11, 12, 13, 17, 19, 21, 22, 23, que faltan en Charivari. Según E. I. Fox, estas fechas deberían pertenecer a su redacción primitiva; pero, como suavizarían el tono polémico del libro, fueron suprimidas por su autor en una redacción posterior [diario íntimo].

(1898) Soledades, insiste en las anotaciones diarias, aunque sin fechas [dietario].

(1901) Diario de un enfermo, novela. Si «Fragmentos de un diario», en Bohemia, era la versión privada de Charivari, Diario de un enfermo parece ser la continuación

\footnotetext{
${ }^{34}$ J. AMIEL, op. cit., 104.

${ }^{35}$ Ibídem.
} 
intimista de «Fragmentos de un diario», cuyas anotaciones, acabadas en marzo de 1897, parecen retomarse en las del Diario de un enfermo, que empieza el 15-XI1898 y acaba el 6-IV-1900 [diario intimo].

(1902) La voluntad [novela autobiográfica cuya tercera parte usa la forma del diario intimo].

(1903) Antonio Azorín [novela autobiográfica cuya tercera parte elige la forma del diario íntimo].

(22-XI-1903) Semanario Alma española, n. ${ }^{\circ} 3$. Azorín colabora con la página titulada: «Juventud triunfante. Autobiografías», donde se retrata a sí mismo en cinco capítulos: Prólogo y disculpa. Mi madre. Mi primera obra literaria. Mi filosofía de las cosas. La rareza de mi carácter, que se incluyen en Las confesiones de un pequeño filósofo [autobiografía].

(1904) Las confesiones de un pequeño filósofo [autobiografía].

(1941) Valencia recoge sus años de estudiante en Valencia [memorias].

(1941) Madrid compila recuerdos de su juventud como periodista en Madrid [memorias].

(1943) Memorias, ampliadas bajo el título Memorias inmemoriales en 1946, refieren su senectud transcurrida en Madrid [memorias].

(1945) París evoca los años de exilio vividos por el autor en la capital francesa [memorias].

\section{RESUMEN}

\section{El diario íntimo, Azorín y la nueva novela, por Montserrat Escartín Gual.}

Este artículo contempla la relación entre el diario, como género literario, y el comienzo de la nueva novela en José Martínez Ruiz, «Azorín» de una manera semejante al de otros escritores españoles de la generación del '98, como Baroja o Unamuno. Algunas características de su estilo (la intimidad, el uso de la primera persona, el presente perfecto, la sencillez, la sintaxis fragmentaria, etc.) proceden de este estilo. Este artículo, por tanto, estudia las obras de Azorín entre 1897 y 1904, con la intención de ver la presencia del tema autobiográfico en toda su producción de juventud.

\section{SUMMARY}

This article shows the relationship between the diary, as a literary genre, and the beginning of the new roman in José Martínez Ruiz, "Azorín», in a similar way than other spanish writers of the ' 98 generation, as Baroja or Unamuno. Some characteristics of his style (the intimacy, the use of the first persone, the present tense, the simplificity, the fragmentary sintax, etc.) comes from this genre. This article also studies Azorín's works between 1897 to 1904 in order to show the presence of the autobiographic subject in all of his youthful production. 